\title{
CINEMA E EDUCAÇÃO: FUNDAMENTOS E PERSPECTIVAS ${ }^{1}$
}

\author{
Rogério de Almeida* \\ Universidade Federal de São Paulo (FEUSP), São Paulo - SP, Brasil
}

RESUMO: Este artigo tem o objetivo de estudar os fundamentos educativos do cinema em uma abordagem hermenêutica a partir dos resultados de pesquisa teórica financiada pela FAPESP entre 2013 e 2015. Dividido em duas partes, este estudo apresenta, na primeira, as principais abordagens contemporâneas sobre cinema e educação: ferramenta didática para ensino em sala de aula; forma de conhecimento; disposição didática; estudos culturais; aspectos sensíveis e criativos; produtor de sentidos. Após análise dessas vertentes, o artigo apresenta sete fundamentos para pensar a relação cinema e educação: cognitivo, filosófico, estético, mítico, existencial, antropológico e poético. Não são dimensões separáveis, mas que operam em relação de complementaridade e contribuem para a compreensão dos diversos modos pelos quais são produzidos, circulados e interpretados os sentidos e as imagens do cinema.

Palavras-chave: Cinema. Educação. Hermenêutica.

\section{CINEMA AND EDUCATION: PRINCIPLES AND PERSPECTIVES}

ABSTRACT: This paper aims to study the educational principles of cinema through a hermeneutic approach based on the results of theoretical research supported by FAPESP between 2013 and 2015. The study has two parts. At the first one, it presents the main contemporary approaches to cinema and education: classroom teaching tool; knowledge form; didactic disposition; cultural studies; sensitive and creative aspects and sense producer. After analysis of these aspects, the paper presents seven principles to think the relationship cinema and education: cognitive, philosophical, aesthetic, mythical, existential, anthropological and poetic. They are inseparable dimensions but operating in complementary relationship and they contribute to the understanding of the various ways that senses and images of cinema are created, shared and interpreted.

Keywords: Cinema. Education. Hermeneutics. 


\section{CONSIDERAÇÕES INICIAIS}

No início do século XX, o cinema enfrentou uma série de barreiras para que fosse reconhecido como arte (embora nem todo cinema ainda o seja), mais precisamente a sétima, como reivindicou Ricciotto Canudo. O cinema seduziu também os filósofos, muitos dos quais se dedicaram, com maior ou menor empenho, a apontar as relações entre cinema e filosofia (BADIOU, 2004; DELEUZE, 1985, 1990; MERLEAU-PONTY, 1983; ROSSET, 1985, 2010; ZIZEK, 2009), concluindo, de maneira geral, que o cinema não está alheio ao pensamento, podendo ser compreendido como um modo de pensar, como uma experiência filosófica. $\mathrm{O}$ interesse por um cinema que se relacione com a educação também não surgiu hoje. Roquete Pinto, por exemplo, constatava, em 1936, uma função pedagógica dos meios de comunicação de massa (FABRIS, 2008, p. 118), sem contar os numerosos filmes que retratam o ambiente escolar ou a figura do professor, ou mesmo a prática de exibir filmes ou trechos em sala de aula, principalmente a partir do advento do videocassete e, posteriormente, do DVD. No entanto, o interesse acadêmico é recente, tendo aumentado nas últimas duas décadas, por meio da multiplicação de pesquisas e publicações sobre o tema.

Não obstante seu interesse recente, há uma diversidade de perspectivas nas abordagens sobre a relação entre cinema e educação, em partes pela ambiguidade que o último termo carrega, ora se restringindo às abordagens escolares, ora considerado em sentido amplo, associada aos meios pelos quais as sociedades fazem circular seus saberes, costumes, valores, enfim, suas culturas. Como pesquisador e docente, tenho optado predominantemente por esse último aspecto da educação, investigando o que chamo de itinerários de formação, isto é, os caminhos e descaminhos pelos quais somos conduzidos (ou nos conduzimos) ao longo de nosso trajeto antropológico (DURAND, 1997), os quais contribuem para que nos tornemos o que somos (NIETZSCHE, 1983; LARROSA, 2009, 2010). Essas investigações têm se desdobrado em análises de filmes e suas relações com temas e fenômenos do nosso tempo (ALMEIDA, 2011, 2012, 2014a, 2014b) e em reflexões sobre o caráter propriamente formativo do cinema (ALMEIDA, 2013a, 2014c, 2014d).

Com o objetivo de embasar a relação entre cinema e educação, este artigo apresenta os resultados de pesquisa teórica desenvolvida com financiamento da FAPESP de 2013 a 2015 e divide-se em duas partes. Na primeira, delineio algumas perspectivas das pesquisas realizadas na área, traçando algumas considerações a partir de levantamento bibliográfico; na segunda parte, faço uma reflexão sobre 
os fundamentos educativos do cinema, a partir de uma perspectiva hermenêutica, que privilegia os processos de produção e interpretação de sentidos esteticamente experienciados por meio do cinema.

\section{ABORDAGENS SOBRE CINEMA E EDUCAÇÃO}

Os procedimentos metodológicos adotados para o levantamento bibliográfico que serviu de base às explanações das abordagens sobre cinema e educação que ora se seguem não tiveram a pretensão de abranger a totalidade dos estudos sobre o tema. Optou-se, de outro modo, por rastrear em periódicos nacionais e em livros uma série de publicações relacionando cinema e educação, das quais privilegiei, para expor as tendências mais visíveis nos estudos da área, as que julguei mais significativas, tendo em vista alguns critérios. Inicialmente, não tive a intenção de mapear todos os estudos nem quantificá-los; também não objetivei compor um panorama que apresentasse toda a gama de perspectivas. Restringi-me a iluminar parte emblemática desses estudos, os quais servem de baliza para a inserção de minhas próprias pesquisas e reflexões, além de fornecer subsídios para o exercício de fundamentação que faço a seguir e também para futuros estudos na área. Restringi-me também aos estudos específicos sobre cinema e educação, deixando de fora a importante contribuição dos pensadores que se dedicaram a pensar o cinema em relação com a filosofia, a arte, a sociedade etc.

Outro elemento que serviu de baliza, embora não tenha sido critério eliminatório, foi o número de citações que o livro/artigo recebeu, considerando que tal dado, combinado com outros fatores - como se a contribuição é mais recente ou longeva, se foi fomentada por agência de pesquisa, qual o periódico ou editora o publicou -, constitui fonte de referência suplementar para a decisão do pesquisador ${ }^{2}$. Busquei, com tal conjunto de critérios, evitar que alguma vertente importante dos estudos mais recentes (últimos 15 anos) ficasse de fora, embora tenha consciência da impossibilidade de abarcar todos os trabalhos realizados ultimamente (como as teses e as dissertações, por exemplo, além de livros e artigos). Assim, o que busquei por meio dos procedimentos metodológicos explicitados foi evidenciar certas tendências nos estudos sobre cinema e educação, e não o seu mapeamento.

Insistindo ainda na questão dos procedimentos metodológicos, investiu-se numa perspectivação rizomática, na acepção que conferem ao termo Deleuze e Guattari (1995), ao apontarem que o rizoma (as múltiplas raízes de uma planta) se encontra sempre no meio, entre as coisas. "Entre as coisas não designa uma correlação localizável que vai de uma para outra e reciprocamente, mas uma direção 
perpendicular, um movimento transversal que as carrega uma e outra [...]" (DELEUZE; GUATTARI, 1995, p. 36). Em outros termos, trata-se da ideia de sistema aberto, que desobriga o conhecimento de um conjunto inicial de princípios. Assim, é possível chegar ao conhecimento por caminhos distintos, do mesmo modo que o rizoma estabelece a relação entre o solo e a árvore (DELEUZE; GUATTARI, 2011). É o que se buscou realizar metodologicamente neste estudo: não a totalidade das produções acadêmicas sobre a relação entre cinema e educação, mas algumas conexões estabelecidas entre determinadas perspectivas e o tema abordado.

Em linhas gerais, as pesquisas estudadas consideram a relação entre cinema e educação de maneira positiva, validando, inclusive, que se estudem filmes hollywoodianos, ainda que seus interesses mercadológicos requeiram reservas ideológicas, pois, de certo modo, compreende-se que os filmes contemplam a diversidade de olhares que se lança ao mundo e possibilitam uma leitura por meio das imagens.

Entre as perspectivas arroladas, as mais conservadoras defendem o uso dos filmes em sala de aula como ferramenta para fins educacionais, pedagogizando o cinema (NAPOLITANO, 2003; CARMO, 2003). Na direção contrária, há o trabalho de Fabiana Marcello e Rosa Fischer (2011), que consideram o cinema como revelador de realidades, produtor de sentidos. Entre os dois polos, há a abordagem sociológica de Duarte (2002), que considera o cinema como forma de conhecimento. Miranda, Coppola e Rigotti (2006) entendem a organização das imagens fílmicas como uma disposição didática. Há também a contribuição de Fabris (2008) para os estudos culturais e de Bergala (2008) e Fresquet (2013) no dimensionamento dos aspectos sensíveis e criativos do cinema, com substratos extraídos de suas respectivas pesquisas de campo em escolas públicas francesas e brasileiras. A seguir, exponho e comento tais perspectivas.

Rosália Duarte (2002), em Cinema \& Educação, faz um mapeamento das relações entre os termos cobrindo desde o que chama de pedagogia do cinema até o cinema na escola, destacando a história do cinema, sua linguagem e o papel do espectador. O livro termina listando pesquisas em educação que têm os filmes como objeto. A perspectiva adotada pela pesquisadora é sociológica. O cinema é relevante, pois contribui para o processo de socialização realizado pela escola. "Ver filmes é uma prática social tão importante, do ponto de vista da formação cultural e educacional das pessoas, quanto a leitura de obras literárias, filosóficas, sociológicas e tantas mais" (DUARTE, 2002, p. 17). 
A autora continua: "determinadas experiências culturais, associadas a uma certa maneira de ver filmes, acabam interagindo na produção de saberes, identidades, crenças e visões de mundo de um grande contingente de atores sociais" (DUARTE, 2002, p. 19). Em linhas gerais, defende-se que o cinema é uma forma de conhecimento e, como tal, possui o mesmo peso cultural e formativo que os livros. Deriva dessa constatação a necessidade de se aprender a linguagem própria do cinema, já que a posição da câmera, seus movimentos, bem como os elementos visuais e sonoros que participam da feitura do filme, produzem sentido.

Um passo a mais e Rosália Duarte (2002) chega à recepção fílmica, mostrando como o espectador é um sujeito social que interage ativamente na construção dos sentidos que circulam nos filmes. $\mathrm{O}$ espectador se identifica psicologicamente com um aspecto, uma propriedade, um atributo do outro, vivendo com os personagens as circunstâncias dramáticas dispostas na narrativa fílmica (DUARTE, 2002, p. 70-71). Segundo a autora,

[...] o contato com filmes produz, num primeiro momento, apenas imagos entendidos aqui como marcas, traços, impressões, sentimentos - significantes que serão lentamente significados depois, de acordo com os conhecimentos que o indivíduo possui de si próprio, da vida e, sobretudo, da linguagem audiovisual. O domínio progressivo que se adquire dessa linguagem, pela experiência com ela, associado a informações e saberes diversos significa e ressignifica indefinidamente as marcas deixadas em nós pelo contato com narrativas filmicas. (DUARTE, 2002, p. 74)

No capítulo "Cinema na Escola", a autora traça os contornos de uma categoria batizada de "filmes de escola", os quais trazem para as telas problemas e dilemas escolares, para criticar a visão conservadora e romântica dessas produções predominantemente norte-americanas. A autora também critica o fato de se usarem filmes no contexto escolar como ilustração de determinado ponto do currículo programático, e não pelo valor que o filme tem enquanto linguagem artística. $\mathrm{Na}$ sequência, lista uma série de atividades possíveis a partir da exibição de filmes e sua relação com temas a serem debatidos. Duarte reconhece que não é necessário "amarrar" filmes a temáticas ou disciplinas, já que "a maior parte dos filmes pode ser utilizada para discutir os mais variados assuntos. Tudo depende dos objetivos e conteúdos que se deseja desenvolver" (DUARTE, 2002, p. 94). Por fim, recomenda que o professor leve informações sobre o contexto em que o filme foi produzido: país, língua, diretor, ano de lançamento, premiações etc. 
O livro de Duarte cumpre o importante papel de reconhecer o caráter pedagógico do cinema de ficção, isto é, o fato de que o cinema veicula narrativas que influenciam comportamento, sentimento e pensamento, de acordo com a abertura do espectador e sua capacidade de "ler" as imagens que perfazem a narrativa fílmica. Nesse aspecto, suas ponderações não diferem do que constatam pensadores alheios à educação, como Gilles Deleuze (1985, 1990), Clément Rosset (1985, 2010), Edgar Morin (2014), Alain Badiou (2004), Júlio Cabrera (2006), Slavoj Zizek (2009) ou Gilles Lipovetsky e Jean Serroy (2009), que reconhecem o cinema como dispositivo pensante, portanto, uma arte que pensa, faz pensar e dá o que pensar. No entanto, quando introduz o cinema na sala de aula, cai no equívoco mais ou menos difundido de subordiná-lo ao fazer pedagógico, isto é, usá-lo para debater um determinado tema ou desenvolver um conteúdo. É inegável que a autora avança ao considerar que o filme não deve ser mera ilustração de um conteúdo, mas, ao associá-lo a um objetivo a ser atingido por meio dele, é também instrumentalizá-lo.

Assim, se de um lado Duarte reconhece que o cinema tem o mesmo valor e o mesmo peso que a literatura, por outro não reivindica o mesmo tratamento, isto é, que se aborde o cinema de modo autônomo, por meio do estudo de sua história, de sua linguagem, dos principais cineastas, de características estilísticas etc. Particularmente, não defendo a disciplinarização do cinema e não me oponho ao debate de temas a partir do uso de filmes como disparadores. No entanto, chamo atenção para a dificuldade que a escola demonstra ter ao lidar com a explosão dos mass media no século XX. Se até o século XIX a escola era responsável pelo regime das informações e dos bens culturais que seriam (ad)ministrados na formação dos jovens, no século XXI a perda do controle sobre essas instâncias fez a escola encolher, restando pouco de sua função formadora. Parece claro que ainda cumpre papel de socialização, de administração de saberes e de disciplinarização do comportamento, mas com menor influência na formação do gosto, no fornecimento de informações, na distinção dos bens culturais. Como consequência, assiste-se a uma espécie de pedagogização generalizada de tudo o que parece concorrer com a escola na formação cultural dos jovens.

Tudo pode ser pedagogizado, isto é, qualquer coisa inicialmente alheia à escola pode ser usada para se atingirem os fins pedagógicos historicamente assumidos pela instituição. Do rap ao Facebook, do jogo ao cinema, tudo pode ser instrumento de ensino. A pretensa abertura da escola à tecnologia, sua busca pela inserção do novo, éincapaz, no entanto, de produzir o novo, já que seu modus operandi permanece inalterado. 
Exemplo bem acabado da pedagogização do cinema é a obra de Marcos Napolitano (2003) Como usar o cinema na sala de aula, que se constitui como um guia para o professor que deseja "incrementar sua didática" (NAPOLITANO, 2003, p. 7). O objetivo é que os filmes de ficção façam parte dos componentes curriculares, submetidos, portanto, ao modus operandi escolar, com atividades, questões, debates e projetos práticos a serem desenvolvidos em sala de aula. Os filmes deslocam-se da condição de arte cinematográfica para serem reduzidos a produtos pedagógicos, com vistas à "articulação com o currículo e/ou conteúdo discutido, com as habilidades desejadas e com os conceitos discutidos; adequação à faixa etária e etapa específica da classe na relação ensino-aprendizagem" (NAPOLITANO, 2003, p. 16). Assim instrumentalizado, o filme deixa de operar esteticamente, deixa de ser obra de pensamento, de criação, perde sua condição de resistência, de desnaturalização, desveste-se de seu imaginário e de sua condição de obra de arte para servir a propósitos didático-pedagógicos que o transformam em referente de um significado que está em outro lugar que não no próprio filme. Assim considerado, o cinema é um mediador entre os alunos e o conteúdo a ser "discutido", sem que entre na relação o conteúdo propriamente cinematográfico. É essa operação que constitui o que tenho chamado de pedagogização do cinema.

Outro exemplo advém de Leonardo Carmo (2003), que, em seu artigo "O cinema do feitiço contra o feiticeiro", baseia-se em Walter Benjamin para investigar as possibilidades de inserção do cinema na sala de aula. Em sua concepção, o "cinema como prática pedagógica pode fazer o aluno se interessar pelo conhecimento, pela pesquisa, de modo mais vivo e interessante que o ensino tradicional" (CARMO, 2003, p. 72). De certo modo, compreende que o cinema educa, mas para os fins de mercado. A intervenção do professor pode fazer com que o feitiço volte-se contra o feiticeiro, isto é, pode funcionar como contraideologia: o cinema seria uma "práxis social orientada pelo e para o mercado. A escola vai se apropriar desses produtos culturais para seus fins específicos" (CARMO, 2003, p. 85), isto é, tratará "o filme como um instrumento de desalienação dos sentidos" (CARMO, 2003, p. 86). Tal concepção parte do pressuposto de que o aluno/espectador é passivo, portanto, manipulável, e que o cinema, orientado pelo e para o mercado, estaria a serviço da alienação, cabendo ao professor a incumbência de uma pedagogia crítica: "cinéfilos e consumidores de imagens em geral são espectadores passivos. Na realidade, são consumidos pelas imagens. Aprender a ver cinema é realizar esse rito de passagem do espectador passivo para o espectador crítico" (CARMO, 2003, p. 77). Nessa acepção, o 
cinema entraria na escola como uma ferramenta política de crítica aos valores hegemônicos da sociedade capitalista:

O cinema, ou pelo menos o cinema no modelo hegemônico, que é o norteamericano, educa segundo as regras de um mundo social alienado. Entretanto, é preciso reconhecer [nos Estados Unidos] [...] um cinema de dissidência, um cinema de esquerda. (CARMO, 2003, p. 85)

A educação, assim concebida, restringe-se a um papel contraideológico, e o cinema, se abordado criticamente, se converte em antídoto contra seu próprio veneno.

Por outro lado, quando se concebe que a educação é um processo mais amplo que a escolarização, que ocorre em todas as sociedades, mesmo nas ditas primitivas ou arcaicas, e independentemente da existência de instituições educativas como a escola, é possível avançar na compreensão de um cinema que educa não porque ensina determinado conteúdo, mas porque condiciona operações cognitivas próprias da narrativa, além de fornecer material concreto e singular para abstrações mais universalizantes (dimensão do pensamento), porque atua na economia da libido, das paixões e das sensações (dimensão estética), porque fornece modelos de identificação/projeção com os personagens e seus desejos, sonhos, pensamentos (dimensão do imaginário), porque tensiona a relação do homem com o mundo numa dimensão social, psicológica, existencial e mítica. Em poucas palavras, o cinema realiza, no século XX, o que a literatura realizou no XIX, isto é, fornece narrativas simbólicas que orientam a experiência humana no mundo de modo equivalente ao que faziam os mitos nas sociedades antigas.

Assim, o cinema pode ser considerado como "uma produção cultural que não apenas inventa histórias, mas que, na complexidade da produção de sentidos, vai criando, substituindo, limitando, incluindo e excluindo "realidades"' (FABRIS, 2008, p. 120). A autora considera que a educação é um processo cultural mais amplo que os que ocorrem no interior da escola, entendendo que toda pedagogia é cultural e, portanto, "produzida em locais sociais distintos da escola" (FABRIS, 2008, p. 121). Em suas análises fílmicas, a pesquisadora concluiu que a escola pode ganhar muito com os estudos sobre cinema, já que as análises conectam-se com outras áreas do conhecimento, possibilitando que a docência se abra "para outras perguntas, ligadas ao contexto cultural em que tais produções foram inventadas e aos contextos culturais em que circulam" (FABRIS, 2008, p. 130).

Buscando uma relação diferente entre cinema e educação, o artigo "Educação pelo cinema", de Miranda, Coppola e Rigotti 
(2006), traça um paralelo entre o cinema e o livro Orbis Sensualium Pictus, de Comenius ${ }^{3}$. A obra é composta de figuras, nomenclaturas e descrições e é considerada o primeiro livro ilustrado para fins didáticos. Segundo os autores,

O cinema, então, assim como o livro de Comenius, coloca as coisas do mundo numa sequência de imagens e numa arquitetura de lugares que não servem apenas para a compreensão da história que está sendo narrada. Este arranjo fílmico é um arranjo didático, em que o espectador, ao concentrar-se na história, aprende a olhar para o mundo, criando com as imagens uma visão de mundo, uma visão do mundo, das coisas do mundo e do que é importante para cada uma das coisas, ou seja, formas de valoração do mundo. (MIRANDA; COPPOLA; RIGOTTI, 2006, p. 3)

Por essa visão, haveria uma educação visual que iria além da narrativa fílmica, influenciando no modo como concebemos o mundo. É o reconhecimento de que o filme, por meio do arranjo visual de sua narrativa, ensina um modo de olhar para o real. Esse aspecto do cinema foi amplamente discutido por Ismail Xavier (2005), que considera os filmes como discursos mais ou menos opacos, mais ou menos transparentes. Derivam dessa concepção tanto um cinema que é concebido como mostra da realidade (mimese naturalista), quanto um cinema que problematiza o modo como apresenta uma dada realidade (aparição do dispositivo). Nesse sentido, Xavier (2008, p. 15) reconhece que "o cinema que 'educa' é o cinema que faz pensar, não só o cinema, mas as mais variadas experiências e questões que coloca em foco. Ou seja, a questão não é 'passar conteúdos', mas provocar a reflexão", o que torna mais eficaz, ao menos no aspecto educativo, o cinema que recusa a transparência mimética revelando seus maquinários narrativos e autorreferenciais (por exemplo, como faz Godard, Antonioni, David Lynch, Woddy Allen, Greenaway etc.). Adriana Fresquet (2013, p. 93), em seu livro Cinema e educação: reflexões e experiências com professores e estudantes de educação básica, dentro e "fora" da escola, reconhece as

[...] dificuldades que a educação encontra hoje, marchando através de grades curriculares pouco flexíveis, cujos conteúdos fragmentados dificilmente dialogam entre si, em aulas que estão menos voltadas para a aprendizagem do que para o preenchimento dos requisitos das avaliações que os governos propõem, visando a índices de rendimento acadêmico.

E propõe que as escolas públicas sejam escolas de cinema, nas quais professores e alunos realizam filmes visando à incorporação do onírico, do imaginativo e do criativo nas "práticas de emancipação intelectual, ética e estética” (FRESQUET, 2013, p. 112). Segundo a autora, a escola não cumpre mais a função social de moralizar, disciplinar 
e instruir, tornando-se um "espaço de comunicação e troca de aventuras intelectuais, afetivas e sensíveis" (FRESQUET, 2013, p. 96).

Fresquet (2013) critica a instrumentalização do cinema pela escola e propõe que sua utilização se dê por meio da apropriação de uma arte, de modo que os aprendentes lancem novos olhares ao cotidiano, recortando o mundo com a câmera e produzindo significado de modo lúdico. Baseada em pesquisas de campo, a pesquisadora sintetiza sua proposta como "fazer experiências do cinema" e norteia alguns princípios para a sua realização na escola, como ver cinema e "manter a atividade da Escola de Cinema fora da grade curricular, isto é, como atividade optativa, sem nota, preferencialmente" (FRESQUET, 2013, p. 112).

As reflexões de Fresquet (2013) contribuem para o reconhecimento do cinema como uma força cultural capaz não só de educar, mas também de deseducar, isto é, de provocar uma reação ao se instalar como alteridade nos espaços escolares. Nesse sentido, suas experiências são devedoras das concepções de Alain Bergala, cineasta e professor francês que atuou como consultor e conselheiro no projeto de introdução da arte cinematográfica nas escolas públicas inserido no "Plano de cinco anos", concebido pelo Ministério da Educação da França.

Em A hipótese-cinema: pequeno tratado de transmissão do cinema dentro e fora da escola, Bergala (2008) filia-se ao pensamento de Godard para problematizar a relação entre cultura e arte, na qual a primeira aparece como regra, e a segunda, como exceção. Desse modo, mais do que ensinar arte, a escola possibilitaria o encontro com o cinema, compreendido não como linguagem a ser lida, mas como o gesto de criação a ser apreendido. Sua concepção prevê mais do que a inserção do cinema na escola, uma ruptura às suas práticas tradicionais, ao se instalar como um outro que provoca uma experiência à parte dela.

Elabora, então, uma "pedagogia do fragmento" pautada no trabalho com trechos de filmes, com análises centradas no plano, para que se capte a "arte de um cineasta e um momento da história do cinema" (BERGALA, 2008, p. 125). A diferença para a análise fílmica clássica é que a análise de criação não está preocupada com a decodificação do filme, mas busca olhar para as escolhas que o cineasta fez em sua criação. Desse modo, os filmes passam de mero suporte pedagógico de disciplinas e conteúdos para uma vivência cultural escolar, uma iniciação à arte.

Essas concepções de Bergala e Fresquet assinalam a importância de não reduzir o cinema na escola a uma práxis meramente analítica e intelectual, mas sobretudo criativa e sensível, razão pela 
qual apresentam propostas nas quais os alunos empunham câmeras e realizam experiências de cinematografia. Particularmente, inclino-me favoravelmente a toda pedagogia que privilegia a experiência e o fazer em suas práticas. Quando atuava como docente do Ensino Médio, implementei nas aulas de leitura a adaptação de textos literários para o meio audiovisual. Os alunos se organizavam coletivamente para adaptar criativamente (entenda-se com liberdade de alterar a narrativa original) obras clássicas da literatura brasileira. Ao fim do trimestre, apresentavam seus filmes coletivamente e, de maneira informal, realizavam suas críticas e autocríticas. Como não é objetivo deste artigo esmiuçar essa prática pedagógica específica e localizada, limito-me a registrar que a experiência foi rica não só para os alunos, que se envolveram com a atividade, mas também para mim, que pude compreender melhor os processos hermenêuticos envolvidos na recepção das obras por parte dos alunos, que interpretavam de maneira muito particular e plural não só as referidas obras, como também e principalmente a época em que vivemos. Um exemplo concreto para ilustrar: Noite na Taverna, de Alvares de Azevedo (2000), a despeito de sua dramaticidade romântica e pessimista, transformou-se muitas vezes em peças cômicas, irônicas, parodísticas, nas quais o amor deixa de ser o referencial pelo qual se mede o valor da vida. Como entender tal fenômeno? A despeito das múltiplas possibilidades interpretativas, parece-me que os alunos, mesmo sem consciência de que assim procediam, guiavam-se por um modus operandi pós-moderno, de acordo com a concepção de Umberto Eco (1985), pelo qual não rechaçavam ou rompiam com a tradição, mas a retomavam de maneira irônica, abordando o amor indiretamente.

Iniciativas práticas como as de Bergala e Fresquet são contribuições importantes para se pensar a relação do cinema com a educação, fundamentalmente com a realizada nas escolas e, dentre essas, principalmente as públicas. No entanto, as questões que colocam vão muito além da relação do cinema com a educação escolar que aí está. Idealizam uma escola que possa abrigar o cinema de maneira ativa, criativa, sensível e crítica. Mais que isso: esperam que o cinema, como esse outro que adentra a escola para provocar a prática de uma pedagogia tradicional, transforme a própria escola. Ora, parece-me que os pressupostos pedagógicos das práticas cinematográficas na escola seriam igualmente válidos para todas as disciplinas, inclusive por seu potencial de dissolver as fronteiras entre as disciplinas. Assim, em vez das aulas de literatura focadas na história e na estrutura, práticas literárias de produção de narrativas; em vez de assimilação de conceitos sobre a mecânica, produção de artefatos que propiciassem uma experiência científica, com elaboração de hipóteses, reflexão 
sobre métodos, modelos de validação dos resultados etc. O problema que se impõe é que tal abordagem trata menos da relação cinema e educação do que de uma política que visa transformar a escola pelas mãos do cinema, mas desde que a escola se transforme para abrigálo. De todo modo, tal dicotomia se dá no âmbito específico da escola (ou das políticas de escolarização) e de uma maneira possível, entre outras, de a escola se apropriar do cinema. Meu interesse recai menos no aspecto escolar do que em sua dimensão educativa, razão pela qual dirijo minhas pesquisas para os elementos que possibilitariam fundamentar o caráter educativo do cinema.

Nesse sentido, posiciono-me de maneira convergente com a agenda para pesquisas em cinema e educação proposta por Fabiana Marcello e Rosa Fischer (2011), que, dentre seus compromissos, postula que não devemos procurar por algo que esteja escondido nas imagens, o que implica "uma aprendizagem estética a ser desenvolvida, inicialmente, por nós mesmos, [...] crer que o cinema olha para certos temas de hoje e, ao fazer isso, nos convida e nos ensina também a olhálos de outro modo" (MARCELLO; FISCHER, 2011, p. 507). Para isso, é preciso pedagogias do olhar que ultrapassem a noção de que o cinema represente a realidade, pois a "imagem é irredutível às interpretações ou às significações, pois estas são e serão sempre inesgotáveis" (MARCELLO; FISCHER, 2011, p. 508). Recorrendo a Merleau-Ponty (2003 ${ }^{4}$ apud MARCELLO; FISCHER, 2011), as autoras resgatam a noção de estado poético para sublinhar que o cinema não expressa nada além dele próprio: "para quem pesquisa e estuda cinema na educação, o primeiro passo é, efetivamente, perceber um filme, entregar-se a ele, e não tentar de imediato interpretar, analisar" (MARCELLO; FISCHER, 2011, p. 508). Entregue às imagens, em estado poético, o espectador pode experimentar esteticamente o cinema, para depois pensá-lo.

De maneira mais direta, as autoras pontuam:

A proposta é que se explore ao máximo um trabalho com e a partir das imagens,
dos modos pelos quais o diretor construiu a narrativa, das escolhas de planos, de
cores, de fotografia, de trilha sonora, de diálogos e inclusive da seleção de locação
e de atores. O encontro com essas escolhas é o que nos permite entrar em contato
também, e simultaneamente, com um modo de ver o mundo e de nele estar, que
poderá nos sugerir o aprendizado de novas sensibilidades ou de outras maneiras
de estabelecer relação com as diferenças. (MARCELLO; FISCHER, 2011, p. 510)

Como consequência, a alteridade, que é um tema atual da educação, pode ser pensada a partir do cinema, já que a imersão que proporciona, o estado poético, contribui para uma experiência cinematográfica da alteridade. Não se trata de conceber pelo cinema a China e o chinês, a Índia e o indiano, as Filipinas e o filipino, mas 
de presenciar o outro, "sua vida íntima, sua relação com o espaço, sua relação com o mundo" (MARCELLO; FISCHER, 2011, p. 515), sabendo que se trata de um olhar artístico e fragmentado sobre uma realidade ficcional, mas nem por isso dissociada do mundo real.

Assim, as pedagogias do olhar estariam menos voltadas a prescrever e conduzir o olhar dos espectadores, dos alunos, dos professores e mais atentas em compreender os diferentes modos pelos quais são produzidos, circulados e interpretados os sentidos e as imagens do cinema (MARCELLO; FISCHER, 2011, p. 517).

\section{FUNDAMENTOS EDUCATIVOS DO CINEMA}

Compreende-se que o cinema atua em três vetores: como tela (dispositivo, linguagem, arte, discursos, narrativa etc.), espelho (metáfora da identificação/projeção subjetiva do espectador) e janela (proposição de mundo em busca de uma compreensão da realidade) (ALMEIDA, 2014a). Assim considerado, o cinema em seu vetor artístico articula dois polos: o do discurso e o da recepção.

O que a tela do cinema apresenta não é uma realidade fechada em si, mas a proposição de um mundo cuja significação flutua ao sabor dos nossos olhos. Como nos lembra Aumont (2002), a imagem tem uma dupla realidade: é imagem em si e também imagem de algo. A obra cinematográfica é, então, uma janela que recorta o mundo e o apresenta como um ponto a ser visto, um texto a ser lido, uma metáfora cuja compreensão é instável, já que depende tanto do olhar da câmera quanto do olhar do espectador. Esse olhar, ao se projetar sobre a tela, recebe, por sua vez, o reflexo de sua própria imagem (a câmera espelha o olhar do diretor e a tela o do espectador). O que vemos no cinema está sempre sob judice e a apreciação dos autos não se dá em referência a uma lei constituída, mas a partir da vivência de cada um, de sua experiência de vida, mas também de sua experiência estética com o cinema, de sua inflexão intelectual e disponibilidade de ser afetado. O modo como assistimos a um filme espelha o que somos, o que pensamos, o que sentimos, a cultura na qual estamos inseridos...

Portanto, na contramão da concepção depreendida dos trabalhos de Napolitano (2003) ou Carmo (2003), que tendem a enfatizar o aspecto da mimese naturalista (XAVIER, 2005) da narrativa cinematográfica, privilegiando seu caráter representativo, considero o cinema como a invenção de um mundo que dialoga com o mundo concreto e com o mundo do espectador, na mesma linha dos trabalhos de Fresquet (2013) ou Marcello e Fischer (2011). O cinema seria, 
então, a articulação entre o real que lhe ultrapassa e o interior de quem o vê. Aceita essa condição, temos os pressupostos necessários para a fundamentação educativa do cinema, que se dará em sete passos.

Não se trata - é importante alertar - de fragmentar a arte cinematográfica em sete partes, como se perfizessem um conjunto, mas de compreender os fundamentos educativos do cinema como fractais, partes que contêm em si o todo. Dessa forma, podem ser subtraídos ou acrescidos fundamentos sem que o caráter propriamente educativo do cinema - como aqui proposto - seja afetado. Em outras palavras, os fundamentos a seguir delineados funcionam como perspectivas, como modos de ver ou iluminar o fenômeno cinematográfico. Uma analogia possível seria compreender o cinema como uma paisagem. O que chamamos de fundamentos não mais são que os miradores, cujas paisagens - exploradores que somos - paramos para investigar, as quais, embora sejam sempre as mesmas, comportam percepções e saberes diferentes de acordo com o ponto de vista elegido. Elegemos, para nosso percurso em torno do cinema, sete paragens, expressas como fundamentos. O que se fundamenta, portanto, não é o cinema em si, mas a perspectivação de sua dimensão educativa.

1) Fundamento cognitivo: um filme é elaborado pelo cineasta a partir de um argumento e de seu estilo, mas a história do filme só se constrói por meio da atividade cognitiva do espectador. Essa é a tese defendida por David Bordwell (1996), que contraria as teorias que ignoram o papel do espectador na construção das narrativas fílmicas ou o consideram passivo, neutro ou, ainda, vítima da ilusão narrativa (BORDWELL, 1996, p. 30). Em sua concepção teórica, o perceptor exerce uma atividade narrativa que pode ser compreendida como um processo perceptual-cognitivo dinâmico. Esse espectador não é uma pessoa concreta, eu ou você, ou o equivalente ao "leitor ideal", concebido para depreender adequadamente os significados propostos, mas uma entidade hipotética que realiza operações relevantes para a construção da história partindo da representação do filme. Bordwell (1996) não ignora a necessidade de conhecimentos específicos para apreensão de uma narração nem exclui do espectador certas limitações psicológicas, mas o concebe como ativo, de acordo com os protocolos intersubjetivos que podem variar de película a película.

Calcado na teoria construtivista da percepção, Bordwell se interessa pelas inferências que, mesmo inconscientemente, o espectador realiza ao assistir a um filme. A percepção não se separa da cognição; antes se converte em um processo de comprovação ativa de hipóteses a partir dos dados captados. A compreensão não é dada, nessa 
perspectiva, a posteriori, como efeito do que é percebido, mas interfere na própria percepção, ao eleger determinadas combinações em busca de uma antecipação de significado (BORDWELL, 1996, p. 31).

Assistir a um filme requer o envolvimento de um processo psicológico-dinâmico que dispõe vários fatores, como as capacidades perceptivas, o conhecimento prévio e a experiência, o material e a estrutura do próprio filme, de modo que o espectador constrói a história, por meio de inferências e comprovações de hipóteses, a partir da organização das informações operadas narrativa e estilisticamente na película pelos realizadores.

O espectador pensa para construir a história de um filme: quando falta informação, faz inferências e suposições; quando os acontecimentos estão fora de ordem temporal, há um esforço do espectador para colocar os acontecimentos em sequência; há um esforço constante para estabelecer conexões causais entre os acontecimentos, tanto em antecipação, como em retrospectiva (BORDWELL, 1996, p. 33).

2) Fundamento filosófico: assim como a matéria do filósofo é o conceito, a do cineasta é a imagem: "os grandes autores de cinema nos pareceram confrontáveis não apenas com pintores, arquitetos, músicos, mas também com pensadores. Eles pensam com imagensmovimento e com imagens-tempo, em vez de conceitos" (DELEUZE, 1985, p. 8). O primeiro momento da história do cinema seria marcado pelas imagens-movimento, cuja centralidade estaria na montagem, no sequenciamento dos planos. As imagens, no cinema clássico, estão a serviço do movimento, apresentam uma imagem indireta do tempo (DELEUZE, 1985). Já o cinema moderno evidencia a manipulação do tempo, engendra a imagem-tempo, rompe com a primazia da montagem e instaura uma pedagogia da "mostragem", pela qual o tempo é liberado e novas imagens se formam, propiciando, também, a criação de novos conceitos, novos modos de pensar (DELEUZE, 1990).

Com uma abordagem diferente, mas partindo da mesma premissa, Júlio Cabrera (2006, p. 17) considera o cinema como uma "forma de pensamento". Trabalhando com a noção de que o filme é um conceito-imagem, uma sucessão de conceitos, propõe que abordemos o cinema como um "objeto conceitual, como um conceito visual e em movimento" (CABRERA, 2006, p. 17, grifos do autor), que tem a vantagem de não expor simplesmente uma ideia, mas de apresentá-la carregada de emoções, o que autor chama de logopatia.

Alain Badiou (2004, p. 23) defende a ideia de que o cinema é a criação de novas ideias sobre o que é uma ideia. Para expor seu 
pensamento, parte da definição das três tarefas da Filosofia: escolha, distanciamento e exceção. Assim, a Filosofia esclarece as escolhas fundamentais do pensamento, a relação entre termos que geralmente não mantêm nenhuma relação, ou seja, o encontro entre termos estranhos. Esclarece, também, a distância entre o pensamento e o poder, a distância entre o Estado e as verdades. Por fim, esclarece o valor da exceção, do acontecimento e da ruptura (BADIOU, 2004, p. 26-27). Enredada por essas três tarefas, a filosofia encontra no cinema uma situação propícia para a experimentação, pois o cinema encerra um paradoxo: a relação totalmente singular entre o total artifício e a total realidade, a possibilidade de uma cópia da realidade e a dimensão totalmente artificial dessa cópia. Mas há outro paradoxo no cinema: é uma arte de massas, ainda que a arte seja uma categoria aristocrática. Há, na condição do cinema, a relação entre um elemento democrático puro e um elemento aristocrático histórico (BADIOU, 2004, p. 28). Portanto, na visão de Badiou, é preciso que a filosofia pense essa relação paradoxal que o cinema impõe e o pese enquanto possibilidade de ruptura (BADIOU, 2004, p. 32), isto é, como criação de novas ideias para pensarmos.

Clément Rosset $(1985,2010)$ também pensou filosoficamente o cinema, aproximando-o do real para afirmar sua condição de duplo: o cinema nos propõe sem uma outra realidade, ou, ainda, uma outra cena da realidade (ROSSET, 2010, p. 56). O que vemos no cinema é justo uma imagem, e não uma imagem justa, conforme sentenciou Godard (19855 apud ROSSET, 1985, p. 62), isto é, não se trata de uma imagem precisa, adequada, correta da realidade, mas tão somente uma imagem, cuja relação com a realidade jamais será precisa, mas indireta, inadequada, uma brecha a ser preenchida pelos sentidos diversamente produzidos pelos espetadores. Desse modo, a tela é tanto vidro por onde penetra a paisagem, quanto espelho no qual nos refletimos, mas com a tranquilidade de nos sabermos a salvo, suficientemente distantes tanto das atribulações do mundo, quanto de nossas camadas mais profundas do (in)consciente. Rosset (2010, p. 26) compara o espectador ao voyeur, com a diferença de que o voyeur real está sempre angustiado pela possibilidade de ser flagrado, enquanto, no cinema, somos voyeurs tranquilos: sabemos que não seremos surpreendidos por ninguém. Janela Indiscreta, de Alfred Hitchcock (JANELA..., 1954), talvez seja o exemplo mais bem-acabado. O protagonista (não à toa um fotógrafo) observa as janelas como se assistisse a um filme, preenchendo as lacunas do que não sabe (porque não vê) com hipóteses. Nós, espectadores voyeurs, 
o surpreendemos em seu voyeurismo. No entanto, enquanto ele corre riscos diegeticamente reais, nós estamos seguros, provavelmente torcendo para que tudo termine bem.

3) Fundamento estético: etimologicamente aisthesis, de origem grega, significa capacidade de sentir o mundo, de compreendê-lo pelos sentidos, é o exercício das sensações. Historicamente, passou a predominar nas definições filosóficas do termo, principalmente a partir do Iluminismo, certa tendência a reduzir a estética ao estudo da arte e do belo, negligenciando seu potencial vitalista. A arte, então, se viu limitada a uma forma de expressão sensivel sem compromisso com a verdade, portanto, sem relação com a episteme, privilégio da ciência e do pensamento.

Contemporaneamente, a estética ressurge como fabulação, imaginação, criação que não se limita à arte, mas materializa estilos, inclusive e principalmente os estilos de vida. Favaretto (2011, p. 232), por exemplo, assinala que houve um "deslocamento da subjetividade promovido pelas obras da arte". Vattimo (1996) constata que, com o enfraquecimento do pensamento, o mundo converteu-se em interpretação, em fabulação. Marcos Beccari (2015) explora a vinculação entre estética e hermenêutica, constatando que a escolha não se dá mais entre verdade e mentira, mas na experimentação tanto da ausência de sentido (dado trágico) como da multiplicidade de sentidos possíveis (imaginário). O que há de comum nesses estudos é que a estética aparece como uma relação pela qual o homem prova do mundo e o aprova e/ou reprova, em partes ou in totum. Não é somente intuição, mas, sobretudo, sensação.

Para Nietzsche (1995), a existência só se justifica como fenômeno estético. A arte torna a existência suportável: “a tragédia realiza a única justificação aceitável e legítima do sofrimento, da dor da falta de sentido - a justificação artística, extramoral" (GIACOIA JUNIOR, 2014, p. 296). Essa manifestação de uma estética afirmadora da vida sustenta-se em sua gratuidade. Não há razão que justifique a vida, que a aponte como necessária. Mas há o gosto de viver. Aprovação da aparência do mundo.

A revalorização da estética contamina inevitavelmente o cinema, tanto por seu potencial de nos propiciar experiências estéticas, quanto por veicular estéticas diversas, já que faz circular estilos de vida, valores éticos e morais, costumes e culturas distintos. Como argumenta Celso Favaretto (2011), a ampliação do campo da arte e da estética liquidou o princípio moderno de uma arte compromissada com o novo, com a ruptura. "A prática artística está desterritorializada, para bem e para mal; isto é, para o exercício das singularidades ou para 
a efetuação da razão comunicativa, quando não para o oportunismo modista" (FAVARETTO, 2011, p. 105). Esse deslocamento da arte das obras para uma arte de viver manifesta-se na estetização da vida cotidiana: lugares, cenas, acontecimentos.

\footnotetext{
Assim, o alargamento da experiência artística, interessada na transformação dos processos de arte em sensações de vida, permite que se pense na possibilidade de se fundar uma estética generalizada que dê conta das maneiras de viver, da arte de viver (FAVARETTO, 2011, p. 108).
}

Lipovetsky e Serroy (2015) defendem a tese de que o mundo, de três décadas para cá, sofreu uma inflação hiper da estética, com a incorporação por parte do capitalismo das lógicas do estilo e do sonho, da sedução e do divertimento, nos diferentes setores do universo do consumo: "um capitalismo centrado na produção foi substituído por um capitalismo de sedução focalizado nos prazeres dos consumidores por meio das imagens e dos sonhos, das formas e dos relatos" (LIPOVETSKY; SERROY, 2015, p. 42). Na visão dos autores, haveria contemporaneamente duas formas de estética, uma ligada ao divertimento, ao consumo de massa, às atividades lúdicas, ao kitsch, às ideias de facilidade, imediatez e fragmentação consumatória. "A outra corresponde às experiências de prazeres mais controlados e seletivos, mais refinados e raros, às buscas hedonistas de qualidade sensitiva e emocional" (LIPOVETSKY; SERROY, 2015, p. 420). Os autores salientam que uma não exclui a outra, mas desenvolvem-se simultaneamente, razão pela qual torna-se questionável essa divisão, tal comoas divisões entre cultura populareerudita, por exemplo. Entretanto, a despeito dos modos possíveis e diversos com os quais podemos analisar os impactos sociológicos da estetização contemporânea, o que parece certo é o reconhecimento de sua expansão.

Nesse sentido, o cinema, por difundir estéticas, por disseminar sonhos, por incutir desejos e fabricar sensações passa a educar não só o intelecto (fundamentos cognitivos e filosóficos), mas também, e de maneira igualmente importante, a sensibilidade.

4) Fundamento mítico: Gilbert Durand (1981) afirmou que o cinema era a mitologia do século XX, isto é, cumpria o papel de difundir as narrativas fundamentais da aventura humana, seus sonhos, angústias e conflitos. E ilustrou narrando uma conversa que teve com Vittorio de Sica a respeito de seu clássico O Ladrão de Bicicletas, na qual afirmou que o filme é o mito de Orfeu. Dada a surpresa do cineasta, Durand explicou que Eurídice foi substituída pela bicicleta:

Vemos um homem que perdeu Eurídice/bicicleta e que desce sucessivamente a três infernos (tanto quanto me lembro): a feira da ladra, o asilo e as prostitutas, para procurar a pista de sua bicicleta. Tem um guia, Hermes, que é o neto, e 
enfim, exatamente como no esquema, reencontra Eurídice, ou seja, rouba outra bicicleta. E parte nessa bicicleta e é apanhado pela polícia, ou seja, é a catástrofe, exatamente como no mito de Orfeu. E aí a imagem é muito bela [...] Orfeu a chorar humilhado pela polícia e pela multidão hostil, e a criança dá-lhe a mão, é uma imagem muito bela, com que o filme termina. É exatamente o esquema de Hermes condutor, psicopompo que conduz a alma. (DURAND, 1981, p. 73-74)

Surpreso, De Sica concordava com Durand, era verdade, embora jamais tivesse pensado nessa relação. E não era preciso de fato que o cineasta soubesse do mito para atualizá-lo. Segundo Durand (1981, p. 74), as mitologias "são relativamente pobres e só têm um número restrito de elementos míticos que se chamam 'mitemas' e combinações desses elementos em número relativamente simples". Com isso, Durand (1981) quer dizer que as numerosas narrativas que proliferam o tempo todo em todas as épocas são variações das narrativas que acompanham a espécie desde seus primórdios, uma vez que, a despeito da variação de roupagens, haveria invariância nos grandes conflitos que o homem trava com o cosmos, com a vida, com a morte, com o tempo... Como afirma Machado de Assis (1994, p. 3), "a velha caleça de praça, em que pela primeira vez passeaste com a mulher amada, fechadinhos ambos, vale o carro de Apolo. Assim é o homem, assim são as coisas que o cercam”.

Estudando os mitos, Joseph Campbell (1993) propõe o conceito de monomito, inspirado no Finnegans Wake, de James Joyce ${ }^{7}$, apresentando as variáveis possíveis de uma mesma estrutura narrativa: chamado - iniciação - retorno. Assim, o herói de mil faces separa-se de seu grupo e empreende uma aventura para a qual é chamado, tendo que vencer numerosas provas iniciáticas para realizar seu feito heroico e conquistar seu prêmio, o qual pode ser repartido com a sociedade em caso de retorno. Evidentemente, há as narrativas que contemplam chamados não aceitos, provas malogradas e retornos falhos, mas, de modo geral, as narrativas míticas seguiriam essa estrutura.

Baseado na obra de Campbell, Christopher Vogler (2006) escreveu A jornada do escritor: estruturas miticas para escritores, um guia prático que fornece modelos para desenvolvimento de histórias. Como analista de histórias, o autor avaliou mais de dez mil roteiros para os grandes estúdios de Hollywood. O livro em si não acrescenta nada à teoria, e, embora tenha suscitado polêmica, o que nos interessa é o reconhecimento de estruturas míticas na base das narrativas cinematográficas e literárias contemporâneas.

De maneira convergente, Mircea Eliade (1985) também aponta para a sobrevivência do mito, transfigurado em novas narrativas. Isso porque o caráter do mito é a repetição: “um objeto ou uma ação só 
se tornam reais na medida em que imitam ou repetem um arquétipo. Assim, a realidade só é atingida pela repetição ou pela participação" (ELIADE, 1985, p. 49).

$\mathrm{Na}$ vertente filosófica (BADIOU, 2004, p. 34-35) também reconhece o alcance ético do cinema ao apresentar grandes figuras da humanidade em ação, vivendo conflitos da vida humana. O cinema trata da coragem, da justiça, da paixão, da traição, dirigindo-se à humanidade para propor uma mitologia moral, assim como fazia a tragédia grega.

De acordo com Campbell (2010, p. 20-21), as funções do mito - e, por extensão, as funções do cinema - giram em torno da reconciliação de nossa consciência com o mistério do universo, a apresentação de uma imagem interpretativa total desse universo, a imposição de uma ordem moral e o auxílio ao indivíduo em busca de seu centro, de uma congruência com sua cultura, com o universo, com o mistério da própria existência.

5) Fundamento existencial: que pode ser expresso pela reflexão de si a partir da relação dos fundamentos anteriores. Com raiz latina ex-sistere (ex > fora; sistere $>$ ficar em pé), a ideia de existir está ligada ao pasmo de nos percebermos de fora, isto é, quando nos tornamos conscientes de nossa própria consciência. A irrupção da existência é um evento a um só tempo cognitivo, filosófico, estético e mítico, pois aprendemos a pensar sobre o que somos a partir das sensações e dos relatos. A existência é assim irredutível a qualquer dos componentes individualmente considerados. Não somos somente conbecimento, conceito, sensação nem narrativa; no entanto, no gesto mesmo (ou no espanto!) de nos darmos conta de existir, percebemo-nos pensando, sentimo-nos existindo e formulamos relatos sobre o que somos ou julgamos ser.

Há, portanto, uma dupla condição da consciência humana: é consciente de si e do mundo, mas é consciente também de sua consciência. Sabe e sabe que (não) sabe.

\footnotetext{
Na ação, o homem é consciente de sua ação, mas simultânea, prévia ou posteriormente a ela, também é consciente de sua consciência da ação, isto é, possui uma dupla consciência: sabe o que faz e sabe que há um eu, ou self, ou consciência, que sabe de si. Podemos chamar essa consciência de si de reflexiva enquanto a consciência da ação é ativa. (ALMEIDA, 2013b, p. 54)
}

Essa condição é geradora de cultura, pois o homem se descobre finito e atrelado à passagem do tempo (DURAND, 1997). Há uma "brecha antropológica" (MORIN, 1973) que se instaura entre o sujeito e o objeto. A frieza e a insignificância do mundo são alimentadas pelo calor de desejos, pensamentos, sonhos, símbolos, sentidos, relatos: "vivemos o cinema dentro de um estado de dupla consciência" (MORIN, 2014, p. 15, grifos do autor). 
O cinema, se de um lado é obra de cultura, por outro a irradia. Não só por nos colocar em contato com costumes, bens simbólicos, visões de mundo que se aproximam e se distanciam de nossas próprias, mas também por nos fazer olhar para nós mesmos. Simultânea e/ ou posteriormente à assistência de um filme, nossa consciência se confronta consigo mesma diante do que vê, isto é, vê-se em relação a.

Nessa perspectiva, o cinema nos devolve a nós mesmos, mas de um jeito diferente, pois estabelece um novo cenário para que nos exercitemos sobre a percepção (fundamento cognitivo), o pensamento (filosófico), a sensação (estético) e o relato (mítico) de nós mesmos.

Mas há um efeito adicional: ao nos percebermos existindo, percebemos também a existência do Outro, aquele que não sou eu, que é diferente de mim, diverso, distante. Esse hiato entre mim e o outro pode ser preenchido de diversas formas, positivas e/ou negativas, a depender da experiência que o cinema oferece. De todo modo, o cinema nos força a ver o outro e a ver como se fôssemos outro. Aproxima-nos de nós, mas também nos afasta; afasta-nos do outro, mas também nos aproxima. Em qualquer das hipóteses, o cinema nos repertoria de modos de existir para que existamos.

6) Fundamento Antropológico: Edgar Morin (2014) defende a tese de que o cinema é uma invenção tardia, pois o homem produz duplos desde tempos imemoriais. Para ele, o cinema é "gerador de emoções e sonhos" (MORIN, 2014, p. 25). Quando assistimos a um filme, "a ilusão de realidade é inseparável da consciência de que ela é realmente uma ilusão, sem, no entanto, que essa consciência mate o sentimento de realidade" (MORIN, 2014, p. 15). O cinema não é evasivo, dispersivo ou ilusório, pois o espectador sabe que a condição do cinema é semelhante a de um jogo. $\mathrm{O}$ faz-de-conta é o motor que propicia a experiência sensorial, intelectual, psicológica, estética. Por isso, essa dimensão antropológica do cinema não pode ser ignorada em seus fundamentos educativos. O cinema dissemina imaginários.

A obra de ficção é uma pilha radioativa de projeções-identificações. Ela é o produto, objetivado em situações, acontecimentos, personagens e atores, reificando em uma obra de arte os 'devaneios' e a subjetividade de seus autores. [...] O imaginário estético, como todo imaginário, é o reino das carências e aspirações do homem encarnadas e colocadas em situação, tratadas no âmbito de uma ficção. Ele se alimenta das fontes mais profundas e mais intensas da participação afetiva. Por isso mesmo ele nutre as participações afetivas mais intensas e mais profundas também. (MORIN, 2014, p. 124)

É provável que, se não houvesse o cinema, quase nada saberíamos de outras culturas, principalmente as que são mais sombreadas pelas culturas financeira, política e ideologicamente 
dominantes. É evidente que o cinema de circuito comercial e interesse massivo pode nada acrescentar ao multiculturalismo, valendo-se, inclusive, de estereótipos historicamente construídos; no entanto, como penetrar as contradições vivenciadas concretamente por chineses, indianos, turcos, iranianos, filipinos, tailandeses, congoleses, senegaleses ou egípcios? O cinema de ficção, com todas as limitações próprias do gênero, tem contribuído para dar voz a esses povos, bem como aos grupos minoritários, com temas ligados a sexualidade, inclusão, direitos humanos etc.

7) Fundamento poético:

A arte da poesia não consiste em descrever didaticamente as coisas ou expor ideias, mas de criar uma máquina de linguagem que, de maneira quase infalível, coloca o leitor em determinado estado poético. [...] Eis porque a expressão humana pode ser tão arrebatadora no cinema: este não nos proporciona os pensamentos do homem, como o fez o romance durante muito tempo; dá-nos a sua conduta ou o seu comportamento, e nos oferece diretamente esse modo peculiar de estar no mundo, de lidar com as coisas e com os seus semelhantes, que permanece, para nós, visível nos gestos, no olhar, na mímica, definindo com clareza cada pessoa que conhecemos. (MERLEAU-PONTY, 1983, p. 115-116)

O cinema é uma máquina de linguagem que fabrica estados poéticos. A proximidade com o fundamento estético é incontornável, mas há diferenças. Enquanto o estético afeta a sensibilidade como um todo (podemos nos concentrar nas cores de Zhang Yimou ou de Pedro Almodóvar), o poético concentra-se pontualmente em dois eixos: na emoção do espectador e na criação do cineasta.

Não se trata de toda ou qualquer emoção. Sentimos medo, raiva, orgulho, compaixão - há uma gama extensa de emoções e o cinema não nos poupa delas, mas a emoção poética é única, pois remete ao fenômeno da criação ou da transcriação. De repente, deparamo-nos com algo que nos arrebata não por seu conteúdo, mas por seu gesto, estilo, por sua forma. Não esperávamos aquela relação metonímica, essa metáfora, o movimento inesperado da câmera, a entrada triunfal da canção, o efeito da vertigem. É a emoção de presenciar algo que não existia ou cuja existência não tinha sido vista e agora se mostra em toda sua potência. É o aedos cantando temas conhecidos dos gregos, mas com o engenho próprio do momento. Não é o tema que emociona, mas o canto.

Por isso, o eixo da emoção do espectador depende da criação do cineasta. Mark Cousins (2013) dedicou um livro à história do cinema (depois transcriado em documentário) cujo elemento central é a poética. "Ao focar o inovador, em vez de meramente belo, popular ou comercialmente bem-sucedido, estou tentando chegar ao próprio 
motor do mundo do cinema" (COUSINS, 2013, p. 8). É evidente, e o autor reconhece, que há outros modos de abordar a história do cinema ou mesmo do poético. Ezra Pound (2006), por exemplo, além dos inovadores, elege os mestres que, conquanto não tenham inovado, levaram a inovação a uma grandeza ímpar. Shakespeare, por exemplo. Desse modo, "um clássico é clássico não porque esteja conforme certas regras estruturais ou se ajuste a certas definições (das quais o autor clássico provavelmente jamais teve conhecimento). Ele é clássico devido a uma certa juventude eterna e irreprimível" (POUND, 2006, p. 21-22). Essa eterna juventude de que trata Pound é justamente o efeito das grandes criações.

George Steiner (2003), em Gramáticas da criação, após observar que somos dominados por uma sede enorme de explicações (STEINER, 2003, p. 10), define "gramática como a organização articulada de uma percepção, uma reflexão ou uma experiência; como a estrutura nervosa da consciência quando se comunica consigo mesma e com os outros" (STEINER, 2003, p. 14), para afirmar como conquista específica do homo sapiens o tempo futuro. "Só o homem, a princípio, possuiria os meios para alterar seu mundo recorrendo a cláusulas condicionais hipotéticas" (STEINER, 2003, p. 14). A arte inova justamente ao perguntar: $e$ se? A variada gama de respostas possíveis coloca em jogo o virtual, o possível, o que não existe (ainda), o futuro.

O cinema é, então, uma criação de esperança na mesma medida em que a imaginação realiza uma função de esperança (DURAND, 1997). Engendra sonhos e pesadelos. Utopias e distopias. É abertura ao devir. Movimento. De certo modo, é o que Bergala (2008) almeja com a entrada do cinema na escola: que ele possa ser criado pelos alunos, por meio de exercícios e experiências com a câmera, mas também pelo estudo de como os cineastas criaram determinados planos e cenas. Seja como for, a criação ou a transcriação por meio da arte é uma gramática incontornável, pois entranhada na espécie (em conexão com o fundamento antropológico), é sua capacidade de inventar versões do que não aconteceu.

\section{CONSIDERACְ̃̃ES FINAIS}

Há muitos modos de relacionar o cinema e a educação, como busquei mostrar na primeira parte deste artigo, desde abordagens mais conservadoras, que consideram o cinema como uma ferramenta didática a ser usada para o ensino em sala de aula, até abordagens mais ampliadas, que compreendem o cinema como produtor de sentidos. Há perspectivas sociológicas, didáticas, voltadas aos estudos culturais 
e, também, à sua dimensão criativa e sensível. Enfim, as duas últimas décadas têm contribuído mais fortemente para a produção de massa crítica a respeito da relação cinema e educação e a tendência aponta para um crescimento cada vez mais intenso, principalmente quando, junto ao cinema, emparelha-se a ampliada produção audiovisual. A proliferação de telas em tempos atuais, como bem constataram Lipovetsky e Serroy (2009), impõe a necessidade de pesquisas que compreendam seu fenômeno, não só socialmente, mas também dos modos como produzem e fazem circular sentidos, bem como dos modos como os apreendemos e a eles resistimos. Nesse sentido, a visada hermenêutica aqui adotada se alinha a essa necessidade de compreensão, pois não se trata de empreender teorias que expressem interpretações mais ou menos adequadas à realidade, mas de entender que a realidade é constituída por nossas interpretações e que elas não estão isentas de esquematizações, paradigmas e perspectivas construídas cognitiva, histórica e ideologicamente (GRONDIN, 2006, p. 123). Por essa razão, menos que julgar as abordagens aqui arroladas, buscou-se compreender suas motivações e as concepções que as ancoraram.

Com o intuito de enriquecer os debates, foram apresentados sete fundamentos educativos do cinema, engendrados hermeneuticamente, isto é, por um viés atento à pluralidade das interpretações e seus intentos de compreender a produção, a circulação e a recepção de sentidos. Menos que uma tentativa de sistematização que visasse adequar o fenômeno à teoria ou superar as abordagens estudadas na primeira parte do artigo, o objetivo foi cartografar caminhos possíveis, confirmando a potencialidade de abordar o cinema com uma visada educativa.

\section{REFERÊNCIAS}

ALMEIDA, Rogério de. Rashômon. In: ALMEIDA, R.; FERREIRA-SANTOS, M. (Org.). O Cinema como Itinerário de Formação. São Paulo: Képos, 2011. p. 151-174.

ALMEIDA, Rogério de. Meia-noite em Paris. In: ALMEIDA, R.; FERREIRA-SANTOS, M. (Org.). Cinema e Contemporaneidade. São Paulo: Képos, 2012. p. 39-52.

ALMEIDA, Rogério de. O imaginário cinematográfico e a formação do homem. In: RODRIGUES, A. J. (Org.). Formação de professores: teoria e pesquisa. São Paulo: Factash, 2013a. p. 179-195.

ALMEIDA, Rogério de. Considerações sobre as bases de uma filosofia trágica. Revista Diálogos Interdisciplinares, São Paulo, v. 2, n. 3, p. 52-63, 2013 b.

ALMEIDA, Rogério de. Possibilidades formativas do cinema. Revista Rebeca, São Paulo, v. 6, jul./dez. 2014a.

ALMEIDA, Rogério de; FERREIRA-SANTOS, Marcos. O cinema e as possibilidades do real: um prólogo ao diálogo. In: ALMEIDA, R.; FERREIRA-SANTOS, M. (Org.). O cinema e as possibilidades do real. São Paulo: Képos, 2014b. p. 9-18. 
ALMEIDA, Rogério de. Cópias sem original: o real em "Um alguém apaixonado", de Abbas Kiarostami. In: ALMEIDA, R.; FERREIRA-SANTOS, M. (Orgs.). O cinema e as possibilidades do real. São Paulo: Képos, 2014c. p. 55-70.

ALMEIDA, Rogério de. O duplo e a ilusão no filme "Clube da Luta". Revista Sessões do Imaginário, Porto Alegre, v. 19, n. 32, p. 26-34, 2014d.

AZEVEDO, Álvares. Obra Completa. Rio de Janeiro: Nova Aguilar, 2000.

ASSIS, Machado de. Obra Completa. Rio de Janeiro: Nova Aguilar, 1994. v. 2. Disponível em: <http://www.dominiopublico.gov.br/download/texto/bv000257.pdf>. Acesso em: 5 ago. 2015.

AUMONT, Jacques et al. A estética do filme. Campinas-SP: Papirus, 2002.

BADIOU, Alain. El cine como experimentación filosófica. In: YOEL, Geraldo (Org.). Pensar el cine 1: imagen, ética y filosofía. Buenos Aires: Manantial, 2004.

BECCARI, M. Articulações simbólicas: uma filosofia do design sob o prisma de uma hermenêutica trágica. 2015. 181 f. Tese (Doutorado em Educação) - Faculdade de Educação, Universidade de São Paulo, São Paulo, 2015.

BERGALA, Alain. A hipótese-cinema: pequeno tratado de transmissão do cinema dentro e fora da escola. Rio de Janeiro: Booklink; CINEAD-LISE-FE/UFRJ, 2008.

BORDWELL, David. La narración en el cine de ficción. Barcelona, Buenos Aires, Cidade do México: Paidós, 1996.

CABRERA, Julio. O cinema pensa: uma introdução à filosofia através dos filmes. Rio de Janeiro: Rocco, 2006.

CAMPBELL, J. O herói de mil faces. São Paulo: Cultrix: Pensamento, 1993.

CAMPBELL, Joseph. As máscaras de Deus: mitologia primitiva. São Paulo: Palas Athena, 2010.

CARMO, Leonardo. O cinema do feitiço contra o feiticeiro. Revista Iberoamericana de Educação, Canoas, n. 32, p. 71-94, 2003.

COUSINS, Mark. História do cinema: dos clássicos mudos ao cinema moderno. São Paulo: Martins Fontes, 2013.

DELEUZE, Gilles. Cinema: imagem-movimento. São Paulo: Brasiliense, 1985.

DELEUZE, Gilles. Cinema: imagem-tempo. São Paulo: Brasiliense, 1990.

DELEUZE, Gilles; GUATTARI, Félix. Mil platôs. São Paulo: Editora 34, 1995. v. 1.

DELEUZE, Gilles; GUATTARI, Félix. Mil platôs. São Paulo: Editora 34, 2011. v. 2.

DUARTE, Rosália. Cinema \& Educação. Belo Horizonte: Autêntica, 2002.

DURAND, Gilbert. As estruturas antropológicas do imaginário. São Paulo: Martins Fontes, 1997.

DURAND, Gilbert. Mito, símbolo e mitodologia. Lisboa: Editorial Presença, 1981.

ECO, Umberto. Pós-Escrito ao Nome da Rosa. Rio de Janeiro: Nova Fronteira, 1985.

ELIADE, Mircea. O mito do eterno retorno. Lisboa: Edições 70, 1985.

FABRIS, Elí Henn. Cinema e Educação: um caminho metodológico. Educação e Realidade, Porto Alegre, v. 33, n. 1, p. 117-134, jan./jun. 2008.

FAVARETTO, C. Arte Contemporânea e Educação. Revista Iberoamericana de Educação, Canoas, n. 53, p. 225-235, 2010.

FAVARETTO, Celso F. Deslocamentos: entre a arte e a vida. ARS, São Paulo, v. 9, p. 94-109, 2011.

FRESQUET, Adriana. Cinema e educação: reflexões e experiências com professores e estudantes de educação básica, dentro e "fora" da escola. Belo Horizonte: Autêntica, 2013. 
GIACOIA JUNIOR, Oswaldo. Nietzsche: o humano como memória e como promessa. Petrópolis: Vozes, 2014.

GRONDIN, Jean. L’herméneutique. Paris: PUF, 2006.

JANELA indiscreta. Título original: Rear window. Direção: Alfred Hitchcock. EUA: Universal Pictures, 1954.

LARROSA, Jorge. Nietzsche \& a Educação. Belo Horizonte: Autêntica, 2009.

LARROSA, Jorge. Pedagogia Profana. Danças, piruetas e mascaradas. Belo Horizonte: Autêntica, 2010.

LIPOVETSKY, Gilles; SERROY, Jean. A estetização do mundo: viver na era do capitalismo artista. São Paulo: Companhia das Letras, 2015.

LIPOVETSKY, Gilles; SERROY, Jean. A Tela Global: mídias culturais e cinema na era hipermoderna. Porto Alegre: Sulina, 2009.

MARCELLO, Fabiana de A.; FISCHER, Rosa Maria B. Tópicos para pensar a pesquisa em cinema e educação. Educação e Realidade, Porto Alegre, v. 36, n. 2, p. 505-519, 2011.

MERLEAU-PONTY, Marcel. O cinema e a nova psicologia. In: XAVIER, Ismail (Org.). A experiência do cinema. Rio de Janeiro: Graal, 1983. p. 101-117.

MIRANDA, C. E. A.; COPPOLA, G. D.; RIGOTTI, G. F. A Educação pelo cinema. Educação e Cinema, Campinas, 2006. Disponível em: < https://www.fe.unicamp.br/ olho/publicações.html>. Acesso em: 15 jul. 2015.

MORIN, Edgar. O paradigma perdido: a natureza humana. Lisboa: Europa-América, 1973.

MORIN, Edgar. O cinema ou o homem imaginário: ensaio de antropologia sociológica. São Paulo: É Realizações, 2014.

NAPOLITANO, Marcos. Como usar o cinema na sala de aula. São Paulo: Contexto, 2003.

NIETZSCHE, Friedrich. Obras Incompletas. São Paulo: Abril Cultural, 1983. (Os Pensadores)

NIETZSCHE, Friedrich. Ecce Homo: por que escrevo tão bons livros. São Paulo: Companhia das Letras, 1995.

POUND, Ezra. ABC da literatura. São Paulo: Cultrix, 2006.

ROSSET, Clément. L’objet singulier. Paris: Minuit, 1985.

ROSSET, Clément. Reflexiones sobre Cine. Buenos Aires: El cuenco de Plata, 2010.

STEINER, George. Gramáticas da criação. São Paulo: Globo, 2003.

VATTIMO, G. O fim da modernidade: niilismo e hermenêutica na cultura pós-moderna. São Paulo: Martins Fontes, 1996.

VOGLER, Christopher. A jornada do escritor: estruturas míticas para escritores. Rio de Janeiro: Nova Fronteira, 2006.

XAVIER, Ismail. O discurso cinematográfico: opacidade e transparência. São Paulo: Paz e Terra, 2005.

XAVIER, Ismail. Um cinema que "educa" é um cinema que (nos) faz pensar. Entrevista. Revista Educação e Realidade, Porto Alegre, v. 33, n. 1, p. 13-20, 2008.

ZIZEK, Slavoj. Lacrimae Rerum. São Paulo: Boitempo Editorial, 2009.

\section{NOTAS}

${ }^{1}$ Este artigo apresenta resultados de pesquisa financiada pela FAPESP. 
${ }^{2} \mathrm{O}$ trabalho mais citado, a título de exemplo, é o de Marcos Napolitano (2003), com 477 citações, e o menos citado é o de Miranda, Coppola e Rigotti (2006), com 13. Os demais variam entre 18 e 54 citações.

${ }^{3}$ COMENIUS, João Amós. Orbis Sensualium Pictus. Londom: J. Kirton, 1659.

${ }^{4}$ MERLEAU-PONTY, Maurice. O Cinema e a Nova Psicologia. In: XAVIER, Ismail (Org.). A Experiência do Cinema: antologia. Rio de Janeiro: Graal, Embrafilmes, 2003. p. 101-118.

${ }^{5}$ GODARD, Jean Luc. Jean-Luc Godard par Jean Luc-Godart. In : Cabiers du cinema. Paris: éditions de L'Étoile, 1985.

${ }^{6}$ LADRÃO de bicicleta. Título original: Ladri di biciclette. Direção: Vittorio De Sica. Itália: Produzioni De Sica, 1948.

${ }^{7}$ JOYCE, James. Finnegans wake. London: Faber \& Faber, 1966.

Submetido: 30/08/2015

Aprovado: 26/10/2016

Contato:

Rogério de Almeida

Faculdade de Educação da Universidade de São Paulo (FEUSP) Av. da Universidade, 308, Cidade Universitária, São Paulo $|\mathrm{SP}|$ Brasil

CEP 05.508-040 
